\title{
Histo-Pathological Profile of Oculoplastic Lesions in a Tertiary Hospital
}

\author{
Olusola Joseph Omotoye ${ }^{1 *}$, Abidemi Emmanuel Omonisi² , Iyiade Adeseye Ajayi ${ }^{1}$ and Olanike \\ Folashade Bodunde ${ }^{1}$
}

\author{
${ }^{1}$ Department of Ophthalmology, Ekiti State University Teaching Hospital, Ado Ekiti, Nigeria \\ ${ }^{2}$ Department of Anatomic Pathology, Ekiti State University Teaching Hospital, Ado Ekiti, Nigeria
}

\begin{abstract}
Background: Ocular tissues removed at surgery are sent for histo-pathological diagnosis to differentiate grossly normal tissues from the grievously abnormal tissues. Treatment options of ocular lesions are histologically guided. This study was therefore aimed to review the histo-pathological profile of oculoplastic lesions which can give useful information on the prevalence of these lesions thus help in designing treatment protocol for them.
\end{abstract}

\begin{abstract}
Methods: Histo-pathological records of all oculoplastic samples sent to histopathology department of the hospital from January 2015-July 2018 were retrieved and reviewed. The theatre and clinic records of all patients that had oculoplastic procedures were also examined to compare the clinico-pathological findings with the histological findings and their demographic characteristics.
\end{abstract}

\begin{abstract}
Results: A total of seventy-eight histo-pathological samples were reviewed over the four years period of the study. There were 28 males $(35.9 \%)$ and 50 females $(64.1 \%)$ with $\mathrm{M}$ : F ratio of $1: 1.8$. Females were consistently more affected than males among all age groups. More than $4 / 5^{\text {th }} 67(85.9 \%)$ of the ocular lesions occurred in young, active adult age group of which ocular surface squamous neoplasia constituted the largest proportion. More than $2 / 3^{\text {rd }}$ of the cases $53(67.9 \%)$ had correct clinical diagnosis when correlated with the histological diagnosis. However, the proportion of missed diagnosis was highest in the orbital lesions.
\end{abstract}

Conclusion: A large proportion of the oculoplastic lesions occurred in young, active adult age group. More than $2 / 3^{\text {rd }}$ of the cases had correct clinical diagnosis when correlated with the histological diagnosis. Histo-pathology confirmation is key to the management and prevention of loss of vision and life.

\section{Introduction}

Ocular lesions constitute a major health challenge in Sub-Saharan Africa [1]. It was reported that tumors of the eye and ocular adnexa were more common in Africa than other parts of the world [2]. The sequela of malignant ocular lesions is one of the main reasons why any ocular tissue removed at surgery must are sent for histo-pathological diagnosis to differentiate grossly normal tissues from the grievously abnormal tissues. Clinically, it may be difficult to distinguish invasive squamous cell carcinoma from an intraepithelial lesion or carcinoma in-situ [3]. There are various eye lesions that might be both pathologically dangerous and cosmetically unsightly which need urgent medical treatment. To prevent vision and life loss, prompt diagnosis and appropriate intervention modalities are compulsory. Apart from this, ocular lesions could be misdiagnosed because eye lesions can manifest in diverse clinical signs [4]. This can lead to delay in real-diagnosis, which might eventually result in vision loss and deformity irrespective of whether it is benign or malignant [5]. Therefore, histo- pathology remains the mainstay of diagnosis in tumoral growths [6]. The treatment options are determined by the histological diagnosis of ocular lesions for example ocular surface squamous neoplasia (OSSN) which could be tumor removal with or without cryotherapy, radiotherapy and topical chemotherapy [7]. Simple surgical excision without adjunctive treatment had been reported to be associated with higher rates of recurrence. Recurrence after initial treatment is variable and warrants life-long follow-up in all cases of OSSN [8]. This study was to determine the his-

*Corresponding author: Dr. Olusola Joseph Omotoye, Department of Ophthalmology, Ekiti State University Teaching Hospital, Ado Ekiti, Nigeria, Tel: +234-8034976221

Accepted: February 13, 2021

Published online: February 15, 2021

Citation: Omotoye OJ, Omonisi AE, Ajayi IA, et al. (2021) Histo-Pathological Profile of Oculoplastic Lesions in a Tertiary Hospital. J Ophthalmic Res Ocular Care 4(1):72-76 


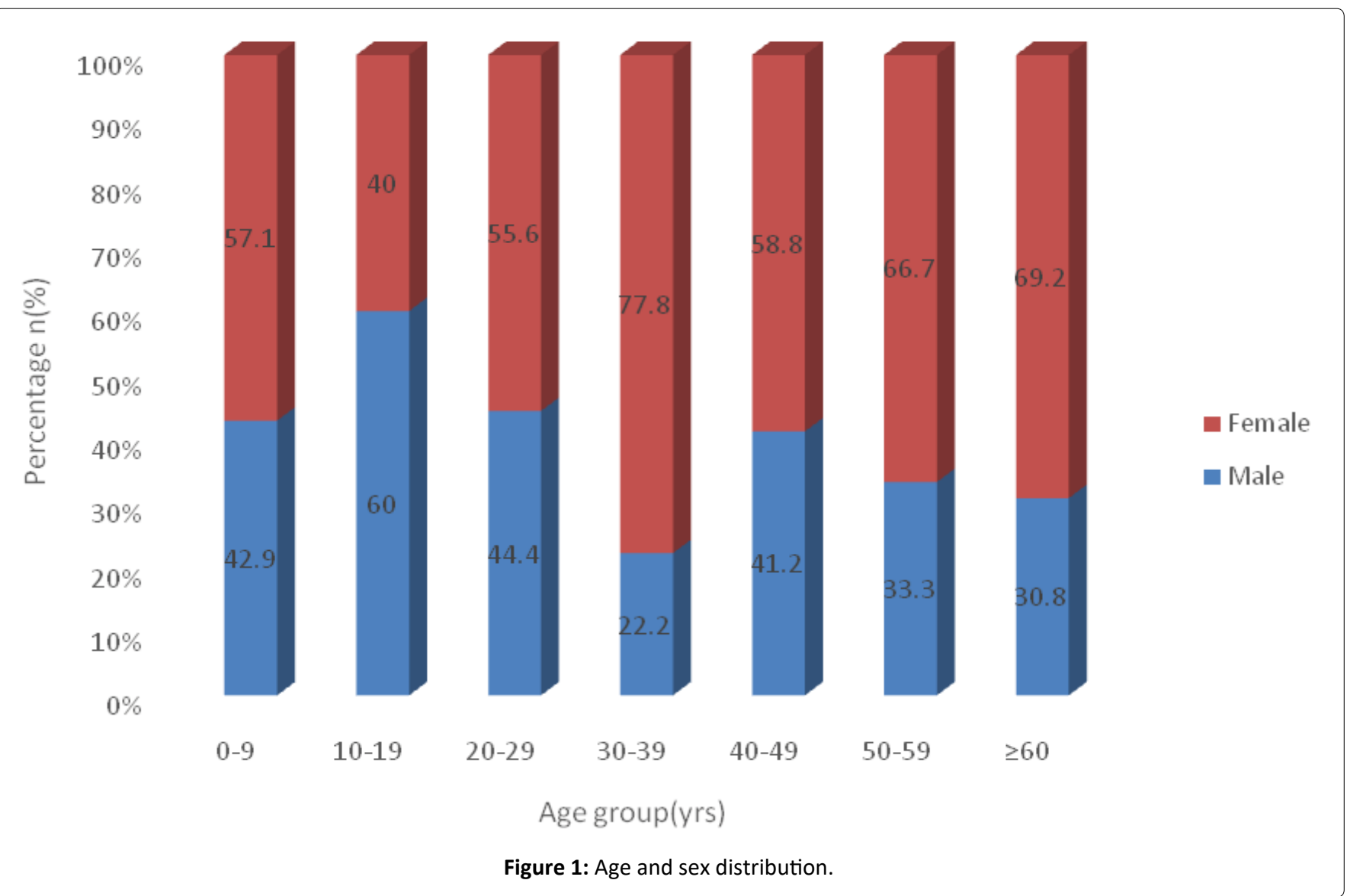

to-pathological profile of oculoplastic lesions which can give useful information on the prevalence of these lesions and thus help in designing treatment protocol for them.

\section{Materials and Methods}

Histo-pathological records of all oculoplastic samples sent to histopathology department of Ekiti state university teaching hospital from January 2015-July 2018 were retrieved and reviewed. The theatre and clinic records of all patients that had oculoplastic procedures were also examined to compare the clinico-pathological findings with the histological findings and their demographic characteristics. Data was recorded and analyzed using Statistical Package for social sciences version 25. Means (Standard deviations) were used to describe the distributions of continuous variables. Categorical variables were described in Percentages. Comparisons of categorical data was performed with the use of Pearson's chi-square test. $P<0.05$ was considered statistically significant. The study was carried out in line with the ethical standards according to the Helsinki Declaration of 1975 as revised in 1983.

Ethical approval was obtained from the institution's ethical review committee though data collection did not directly involve patient's participation.

\section{Results}

A total of seventy-eight histo-pathological samples were reviewed over the four years period of the study. There were 28 males (35.9\%) and 50 females (64.1\%) with M:F ratio of
1:1.8. The age ranges from 3 years to 74 years with mean age of $39.2 \pm 18.16$ years. The right eye was more affected $49(62.8 \%)$ than the left eye $29(37.2 \%)(X 2=5.128, d f=1, p=$ $0.024)$ Figure 1.

Females were consistently more affected than males among all the age groups except at 10-19 age group. More than half $44(56.4 \%)$ of the oculoplastic lesions were found in less than 40 years of age (Table 1). However, 67(85.9\%) of the ocular lesions occurred in over 16 years of age, of which ocular surface squamous neoplasia (OSSN) constituted the largest proportion $32(41.0 \%)$ and the commonest histological type was conjunctival Intraepithelial Neoplasm III. No record of invasive squamous cell carcinoma (SCC) was found (Table 2). The clinical picture of 74 years old woman with left huge conjunctiva-corneal mass (Figure 2A) Conjunctival Intraepithelial Neoplasm III. A full thickness of the squamous epithelial layer with intact basement membrane (Figure 2B).

Clinical picture of a young boy with Dermoid Cyst (Figure $3 A$ ) excisional biopsy of the Dermoid cyst intra operatively (Figure 3B) and histology of Dermoid cyst (Figure 3C).

The commonest ocular site affected was conjunctiva 54(69.2\%) while retina and Orbit were equally affected $3(3.8 \%)$ (Figure 4$)$. More than $2 / 3^{\text {rd }}$ of the cases $53(67.9 \%)$ had correct clinical diagnosis when correlated with the histological diagnosis. The proportion of missed diagnosis was highest in the orbital lesions (Figure 5). 

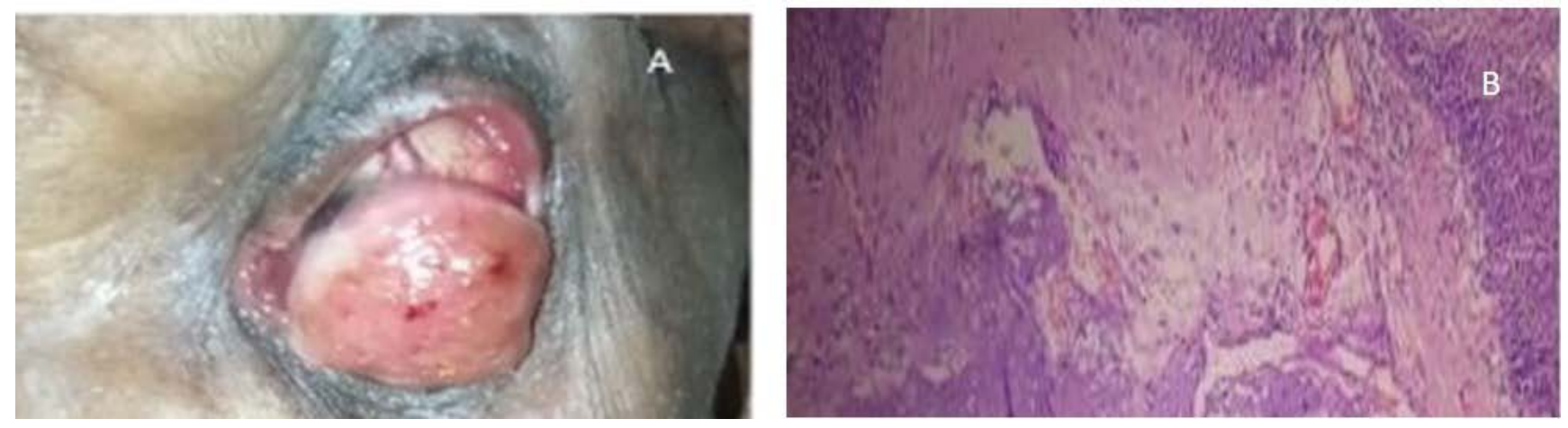

Figure 2: A) Clinical picture of 74 years old woman with left conjunctival mass; B) Conjunctival Intraepithelial Neoplasm III. A full thickness of the squamous epithelial layer with intact basement membrane.
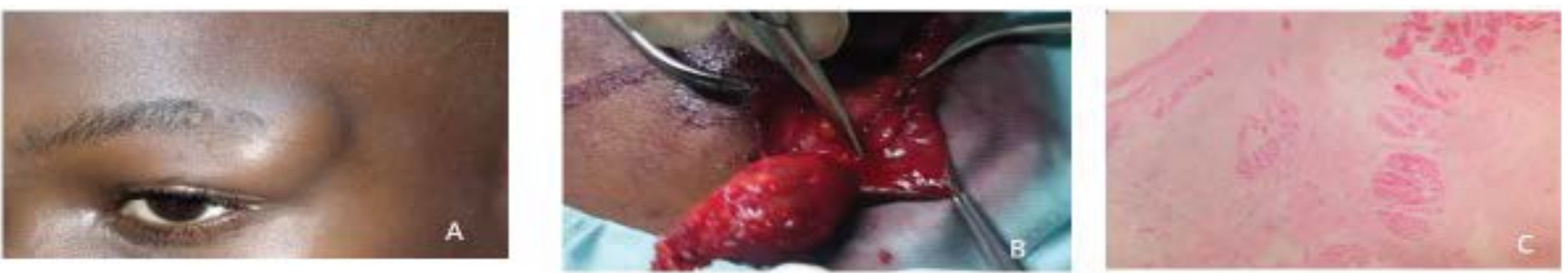

Figure 3: A) Clinical picture of a young boy with dermoid cyst; B) Excisional biopsy of the dermoid cyst intra operatively; C) Histology picture of dermoid cyst.

Table 1: Age and sex distribution.

\begin{tabular}{|l|l|l|l|}
\hline Age group years & Male $n(\%)$ & Female $n(\%)$ & Total $n(\%)$ \\
\hline $0-9$ & $3(42.9)$ & $4(57.1)$ & $7(8.9)$ \\
\hline $10-19$ & $3(60.0)$ & $2(40.0)$ & $5(6.4)$ \\
\hline $20-29$ & $4(44.4)$ & $5(55.5)$ & $9(11.5)$ \\
\hline $30-39$ & $6(26.1)$ & $17(73.9)$ & $23(29.5)$ \\
\hline $40-49$ & $5(38.5)$ & $8(61.5)$ & $13(16.7)$ \\
\hline $50-59$ & $3(37.5)$ & $5(62.5)$ & $8(10.3)$ \\
\hline$\geq 60$ & $4(30.8)$ & $9(69.2)$ & $13(16.7)$ \\
\hline
\end{tabular}

Females were consistently more affected than males among all the age groups except at 10-19 age.

\section{Discussion}

The confirmed histo-pathological cases were predominantly more in females than males in this study. This is contrary to many other studies reported in Nigeria where there was male preponderance [6,9-11] but similar to a study of orbito-oculoplastic lesions in Lagos Nigeria [12]. The female preponderance might be due to the fact that females preferred to utilize the health facility because they are more sensitive to ocular disfigurement as reported in the Lagos study [12]. Ophthalmic lesions are an important cause of morbidity and mortality [6] which can make the sufferer to spend their entire fortune to get solution.

Majority of the patients with these lesions were young, active and productive age group. This was similar to a Lagos study a Southwestern part of the country [12]. This trend can
Table 2: Histological diagnosis by age group.

\begin{tabular}{|c|c|c|}
\hline \multirow[t]{2}{*}{ Variable diagnosis } & \multicolumn{2}{|c|}{ Age group (yrs) } \\
\hline & $\leq 16(\%)$ & $>16(\%)$ \\
\hline${ }^{*}$ OSSN & $0(0)$ & $32(100)$ \\
\hline Conjunctival cyst & $0(0)$ & $7(100)$ \\
\hline Granuloma & $2(28.6)$ & $5(71.4)$ \\
\hline Pinguecula & $0(0)$ & $5(100)$ \\
\hline Papilloma & $0(0)$ & $4(100)$ \\
\hline Conjunctival Neavus & $2(66.7)$ & $1(33.3)$ \\
\hline Neurofibroma & $3(100)$ & $0(0)$ \\
\hline Epidermal inclusion cyst & $0(0)$ & $2(100)$ \\
\hline Pterygium & $1(50)$ & $1(50)$ \\
\hline Dermoid cyst & $0(0)$ & $1(100)$ \\
\hline Dysplasia & $0(0)$ & $1(100)$ \\
\hline Dacrocycele & $0(0)$ & $1(100)$ \\
\hline Capillary haemangioma & $0(0)$ & $1(100)$ \\
\hline Chalazion & $0(0)$ & $1(100)$ \\
\hline Orbital lymphoma & $0(0)$ & $1(100)$ \\
\hline Fibrolipoma & $0(0)$ & $1(100)$ \\
\hline Retinoblastoma & $3(100)$ & $0(0)$ \\
\hline Teratoma & $0(0)$ & $1(100)$ \\
\hline Verrucae & $0(0)$ & $2(100)$ \\
\hline Total & 11(14.1) & $67(85.9)$ \\
\hline
\end{tabular}

*OSSN: Ocular surface squamous neoplasia. 


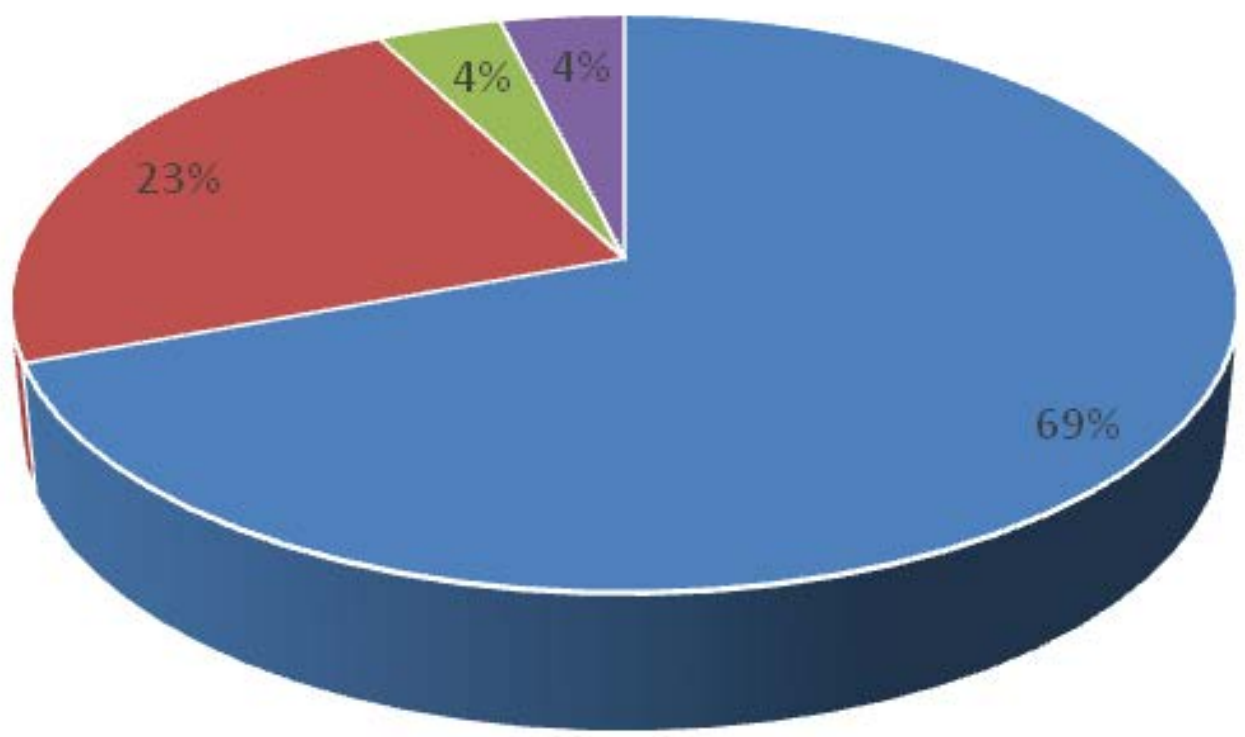

- Conjunctiva

- Lid

Orbit

- Retina

Figure 4: Clinical diagnosis by anatomical site.

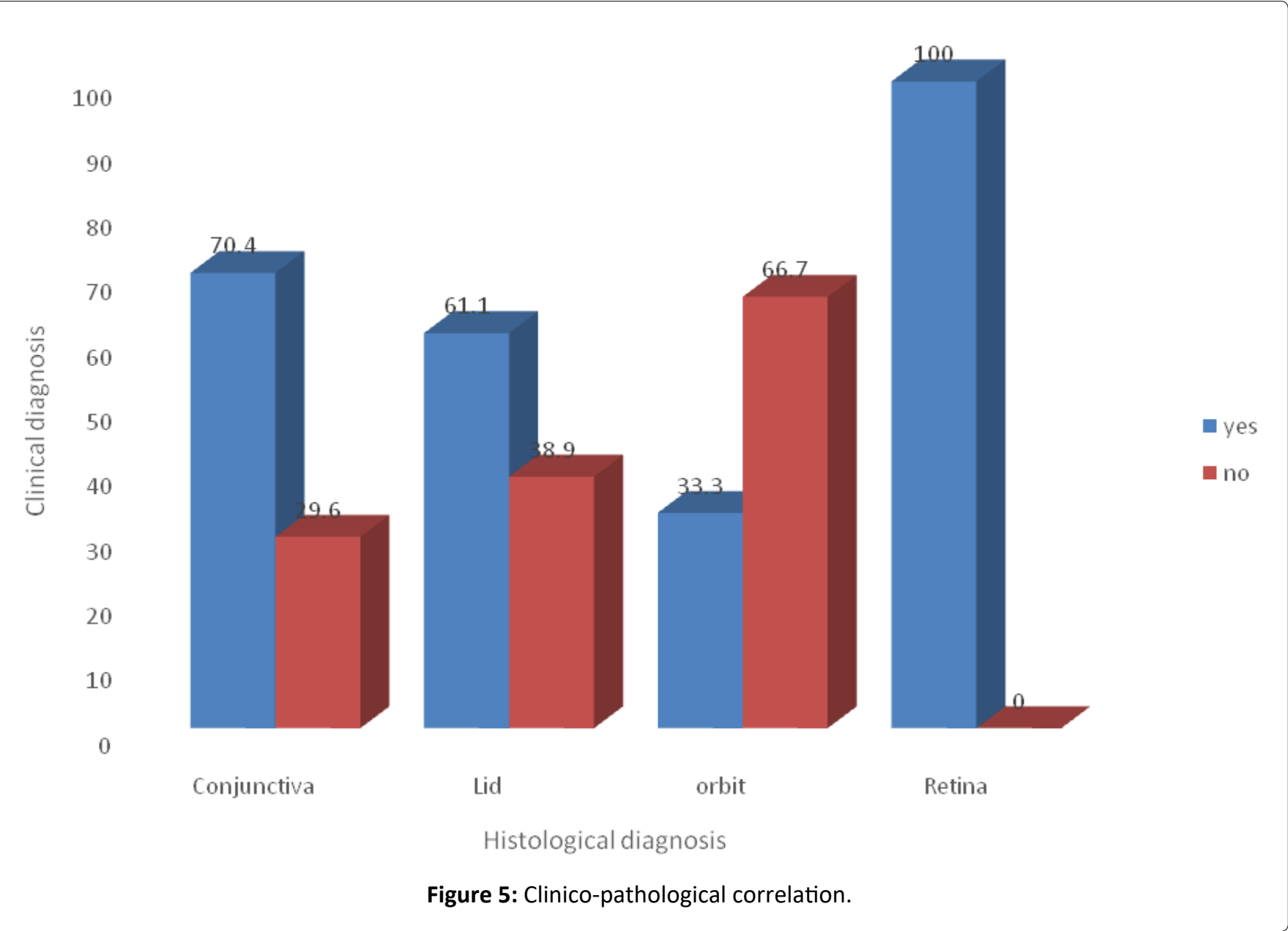

negatively affect the economic growth of a developing nation. To prevent this negative economic growth, these conditions must be diagnosed correctly and treated promptly.

Top most of the confirmed histology diagnosis was ocular surface squamous neoplasia (OSSN) which was found in adult age group. This lesion ranged from mild dysplasia to invasive form of squamous cell carcinoma $[13,14]$. In this study, the commonest histological type found was conjunctival Intraepithelial Neoplasm III with no record of invasive squamous cell carcinoma (SCC).OSSN has been reported as the commonest 
malignancy of the conjunctiva in the world and Sub-Saharan Africa, though, regarded as low-grade malignancy [15-17]. The clinical symptoms are generally nonspecific initially [18]. thus the lesion might be thought to be benign. This may lead to delay in making diagnosis which has been reported to have considerable effects on ocular morbidity and mortality [19]. Timely detection, prompt histological diagnosis and appropriate treatment modalities are the path ways to avert these fatal sequelae. The low incidence of histo-pathological diagnosis of pterygium in this study was due to the fact that most of the cases were not sent for histological diagnosis which is similar to a study in North Central part of Nigeria [1] but contrary to a study in Benin where there was a hospital policy to send all excised tissues for histo-pathological diagnosis [6]. This policy should be embraced in this hospital in order to overcome the challenges of distinguishing early neoplastic from benign lesions [19]. Conjunctiva had the largest proportion of various ocular lesions in this study $[2,9,20]$. Retinoblastoma which is the most childhood malignancy was found to be rare and in children similar to other reports [9-11].

The lid lesions constituted one fifth of all the histological confirmed cases in this study. This is second to conjunctival lesions for which cystic lesions were the commonest unlike the previous study in this centre where chalazion was among the commonest eyelid disorders [21]. This is due to the fact most chalazion lesions were not sent for histo-pathological diagnosis.

More than $2 / 3^{\text {rd }}$ of the cases had correct clinical diagnosis when correlated with the histological diagnosis. This was as a result of high index of suspicion due the clinical presentations. This will enhance the timely commencement of appropriate treatment modalities in these cases. The proportion of missed diagnosis was highest in the orbital lesions which presented with diverse clinical signs thus confirmation by histology is germane to their management.

\section{Conclusion}

A large proportion of the oculoplastic lesions occurred in young, active adult age group. More than $2 / 3^{\text {rd }}$ of the cases had correct clinical diagnosis when correlated with the histological diagnosis. Histo-pathology confirmation is key to the management and prevention of loss vision and life. The policy of sending all ocular tissues for histology should be embraced in this hospital in apparently benign lesions like pterygium that cannot be agreed by anin-experienced ophthalmologist who will think it will be necessary only when ocular surface lesions do not look like pterygium according to characters and course of the lesion.

\section{Authors Contributions}

OJ Omotoye - Concept, design, drafting and final approval; AE Omonisi - Design, drafting, critical analysis, final approval; IA Ajayi - Design, drafting, critical analysis and final approval; OF Bodunde - Design, drafting and final approval.

\section{References}

1. Onwubuya IM, Owoyele TM, Olaofe OO, et al. (2015) Morphological spectrum of orbitoocular diseases in a tertiary health centre in Keffi, North Central Nigeria. Adv Med 2015: 619414.
2. Umar AB, Ochicha O, lliyasu $Y$ (2012) A pathologic review of ophthalmic tumors in Kano, Northern Nigeria. NJBCS 9: 23-26.

3. Padmavathi P, Prabha DP, Ather M, et al. (2016) Clinical behaviour of ocular surface squamous neoplasia (OSSN) in HIV positive patients. MRIMS J H Sc 4: 114-117.

4. Yang $\mathrm{M}$, Wang $\mathrm{W}$, Yan JH, et al. (2015) Eye tumors misdiagnosed as glaucoma. Chin Med J 128: 273-276.

5. Rao AA, Naheedy JH, Chen JYY, et al. (2013) A clinical update and radiologic review of pediatric orbital and ocular tumors. J Oncol 2013: 975908.

6. Akpe BA, Omoti AE, Iyasele ET (2009) Histopathology of ocular tumor specimens in Benin City, Nigeria. J Ophthalmic Vis Res 4: 232.

7. Gupta A, Muecke J (2010) Treatment of ocular surface squamous neoplasia with Mitomycin C. Br J Ophthalmol 94: 555-558.

8. Tananuvat N, Lertprasertsuke N (2012) Ocular surface squamous neoplasia. Intraepithelial neoplasia. Publisher InTech Published online 8: 35-62.

9. Anunobi C, Akinsola F, Abdulkareem F, et al. (2008) Orbito-ocular lesions in Lagos. Niger Postgrad Med J 15: 146-151.

10. Aligbe J, Igbokwe U, Akang E (2003) Histopathology of orbito-ocular diseases seen at University of Benin Teaching Hospital, Benin City. Niger Postgrad Med J 10: 37-41.

11. Chuka OC, Uche N, Kizor AN (2008) Orbito-ocular neoplasms in Enugu, South-Eastern, Nigeria. West Afr J Med 27: 144-147.

12. Balogun BG, Adekoya BJ, Balogun MM, et al. (2014) Orbito-oculoplastic diseases in Lagos: A 4-year prospective study. Middle East Afr J Ophthalmol 21: 236-239.

13. Osahon A, Onunu A (2007) Ocular disorders in patients infected with the human immunodeficiency virus at the University of Benin Teaching Hospital, Benin City, Nigeria. Niger J Clin Pract 10: 283-286.

14. Spitzer MS, Batumba NH, Chirambo T, et al. (2008) Ocular surface squamous neoplasia as the first apparent manifestation of HIV infection in Malawi. Clin Exp Ophthalmol 36: 422-425.

15. Pola E, Masanganise R, Rusakaniko S (2003) The trend of ocular surface squamous neoplasia among ocular surface tumour biopsies submitted for histology from Sekuru Kaguvi Eye Unit, Harare between 1996 and 2000. Cent Afri J Med 49: 1-4.

16. Nagaiah G, Stotler C, Orem J, et al. (2010) Ocular surface squamous neoplasia in patients with HIV infection in sub-Saharan Africa. Curr Opin Onco 22: 437-442.

17. Erie JC, Campbell RJ, Liesegang TJ (1986) Conjunctival and corneal intraepithelial and invasive neoplasia. Ophthalmology 93: 176-183.

18. Shields JA, Shields CL (2008) Eyelid, conjunctival, and orbital tumors: An Atlas and textbook. Lippincott Williams \& Wilkins.

19. Nguena MB, van den TJG, Makupa W, et al. (2014) Diagnosing ocular surface squamous neoplasia in East Africa: Case-control study of clinical and in vivo confocal microscopy assessment. Ophthalmology 121: 484-491.

20. Bekibele C, Oluwasola A (2003) A clinicopathological study of orbito-ocular diseases in Ibadan between 1991-1999. Afr J Med Medical Sci 32: 197-202.

21. Olusola O, lyiade A, Kayode A, et al. (2018) Pattern of eyelid disorders in a tertiary health centre, South Western, Nigeria. J Hsr 3: 1-5. 